\title{
Utilization of Satellite Images-Based Indices for Assessment of Al- Hammar Marsh Restoration plan
}

\author{
Bayda A. Dhaidan ${ }^{a}$, Imzahim A. Alwan (D) ${ }^{\text {b }}$, Mahmoud S. Al-Khafaji ${ }^{c}$ \\ ${ }^{a, b}$ Civil Engineering Department, University of Technology, Baghdad, Iraq. \\ ${ }^{\mathrm{c} C i v i l}$ Engineering Department, Nahrain University, Baghdad, Iraq. \\ *Corresponding author Email: bayda.bh1@, gmail.com
}

\section{H I G H L I G H T S}

- Used a series of spectral indices in Ecological wetland assessment.

- Develop a satellite-based model to automated classification of the marshes land cover.

- Spatiotemporal assessment of the efficiency of implementing restoration plans.

\section{A R T I C L E I N F O}

Handling editor: Wasan I. Khalil

Keywords:
NDVI
NDMI
NDWI

Module builder

Al- Hammar Marsh

\begin{abstract}
A B S T R A C T
Wetland landscape characterization is an important component of determining the degree to which wetlands improve environmental conditions. The present study aims to create a model used to automated extraction of the land cover of the western part of the Al-Hammar Marsh south of Iraq, and then monitor the change in land cover overtime. A model builder in ArcGIS created based on a series of spectral-based indices included the Normalized Difference Vegetation Index (NDVI), the Normalized Difference Moisture Index (NDMI), and the Normalized Difference Water Index (NDWI), the OLI satellite images from 2013 to 2020, ENVI 5.3 and ArcGIS 10.4 were used to achieve this goal. The results were six land cover classes: water, density vegetation, medium dense vegetation, low dense vegetation, wet barren land and, dry barren land. From the monitoring of the changing trend, it is clear that there is no improvement in the vegetation area, only a slight temporal improvement to $48 \%$ in 2017 , an increase in water area for the years 2019 and 2020 to $47.33 \%$, and $42.85 \%$ from the total area of the marsh respectively. The highest percentage was in 2019 while decreasing to the lowest rate of $14.05 \%$ for the year 2018 . The developed model was accepted and can be applied for reflectance Landsat 8 data in the study area and can be applied in the southern Iraqi marshes. It also can be applied to other types of sensors, but according to determinants.
\end{abstract}

\section{Introduction}

The southern Iraqi marshlands are the largest wetland in the continent of Asia. These marshlands are extended over more than $20000 \mathrm{~km} 2$ of the area surrounding the confluence of the Euphrates and Tigris Rivers in southern Iraq and part of southwestern Iran. These marshes, with their exceptional biodiversity, represent an important social and economic ecosystem for the natural and human life in the region. Provides natural controls over changes in the climate and central habitat of unique plant and animal species [1].

These marshes with their unique ecosystems dried up in an organized way for more than a decade, as a result, the whole ecosystem utterly destroyed. After 2003, the Iraqi Ministry of Water Resources (IMoWR) developed ambitious plans to revitalize the Iraqi marshes and restore their ecosystems $[1,2]$. Since then, the concerned institutions have been trying hard to implement these plans. However, great challenges and obstacles are facing the implementation of these plans, such as the severe shortage of available water resources, demographic changes, and oil exploration and extraction works. According to these challenges, an integrated assessment is required of the extent to which the restoration plan has actually been achieved. An adequate assessment required applying an efficient methodology by using practical tools that ensure integrated spatiotemporal evaluation of the marsh's restoration concerns features. Wetland mapping and studying the spatiotemporal changes in vegetation covers and other related ecological elements are the first steps towards the acquisition of scientific knowledge on wetland habitats [3]. The satellite-based and Geographical Information System (GIS) methodologies are effective tools used to monitor and assess the spatiotemporal change in land cover, and some effective features of ecological systems. 
A large number of researchers were presented and discussed the use of remote sensing and GIS techniques in monitoring and assessing the degradation of wetlands and investigation of a wide range of activities.

[4] Developed the Iraqi marshlands NDVI thresholds for Landsat satellite images, NDVI values greater than 0.125 represented vegetation cover, NDVI values between 0.125 and 0.25 represented sparse vegetation, while medium-density vegetation was associated with NDVI values between 0.25 and 0.5 and Dense vegetation represented area with NDVI values over 0.5 .

[5] Utilized remote sensing techniques to monitor and assess the Trophic State Index (TSI) within Al-Haweizeh Marsh. A series of digital image processing approaches and methods such as layer stack, image subset and converting digital numbers to radiance, were utilized to implement a satellite image-based TSI mapping model. This TSI model was calibrated and validated using sets of measured Secchi depth (SD) and obtained spectrum reflectance from the Landsat ETM image-2006.

[6] Used remote sensing with GIS application to study the change in land cover and land use LCLU in the Iraqi marshes south of Iraq by using Landsat images of MSS, TM, and ETM for different periods between 1973 and 2004 . The NDVI was also applied to extract vegetation cover. The result of classification process showed that there was an increase in the barren land in the year 2000 with highly decrease in water bodies while in 2004 there was a clear increase in the area of the main marshes by more than $50 \%$ after their restoration.

The changes happened in the main features (water, vegetation, and soil) of Al-Hammar Marsh was monitored via applying an unsupervised classification technique called (Color Extracting Technique) to classify the satellite images of MSS 1973, TM 1990, ETM+ 2000, 2002, and MODIS 2009, 2010 [7]. Also, satellite images of Landsat MSS, TM, ETM, and MODIS satellite images for lack of space imagery satellite Landsat were used to monitor the AL-Hammar Marsh for the period between the years 1973-2010. Erdas Imagine 9.1 software was used to classify these images and the maps were produced by using Arc Map program v.9.3 [8]. [9]Prepared a hydrological and water quality routing model for the Al Dalmaj Marsh, Main Outfall Drain (MOD)and Al Hammar Marsh system based on the mass conservation low (mass balance model). Two scenarios were applied for Al- Dalmaj Marsh, which is located upstream of Al Hammar Marsh and is primarily fed by the MOD water, and the outfall of this marsh is discharged back into the MOD, where the MOD is one of the feeding sources of Al Hammar Marsh based on the incoming and outgoing discharge. The results of using these models with these flow scenarios and inundation cases show that the water salinity within Al-Dalmaj Marsh and Al Hammar Marsh was above the acceptable range of international standards in the majority of the studied cases.

Moreover, [10] studied the spatiotemporal changes of Lake Urmia in Iran for the period 2000-2013 using Landsat 5-TM, 7-ETM+, and 8-OLI satellite images. The different satellite-derived indexes including Normalized Difference Water Index (NDWI), Modified NDWI (MNDWI), Normalized Difference Moisture Index (NDMI), Water Ratio Index (WRI), Normalized Difference Vegetation Index (NDVI), and Automated Water Extraction Index (AWEI) were investigated to extract the surface water distribution from Landsat data. Overall, the NDWI was found superior to other indexes and hence it was used to model the spatiotemporal changes of the lake. However,[11] monitoring changes in the southern Iraqi marshes using Landsat images TM and ETM+ for the period from 1990 to 2015. Supervised classification with ERDAS IMAGINE 2014 and ARC GIS 10.2 programs was used to produce three land cover maps for the study area. The Transformed Normalized Difference Vegetation Index (TNDVI) and NDWI were used to extract natural vegetation and water in the study area. The results showed that deterioration occurred largely in the waters of marshes and vegetation area from 1990 to 2000, and then this deterioration began to decrease gradually and marshes began to recover from 2000 to 2015 . There is an increase in the surface area of waters of marshes and natural vegetation in 2015 than in 2000, but this increase does not reach the area of water and natural vegetation in the year 1990.[12] developed and applied remote sensing and GIS-based model to estimate and evaluate the spatiotemporal change in some water quality parameters (Temperature, DO, BOD, pH, Turbidity, TSS, TDS, EC, NO3, PO4, and E. coli) of the Dokan lake in Kurdistan Region, Iraq. The multiple linear regression was used to obtain and evaluate the performance of various mathematical models of computing the concentration and values of these water quality parameters based on the spectral reflectance of Landsat 8 OLI. Moreover, a supervised classification method and NDVI were used via [13] to study the changes in land cover of wetlands, dry lands area, and of other land classes for Al-Dalmaj Marsh and near surroundings, Landsat images for different years 1990, 2003, and 2016 were analyzed. The paper showed that the data collected by remote sensing can be used to provide reliable information on the values of vegetation, water, wetlands, and the sustainability of dry land resources. Consequently, this data can be used to develop plans to increase tourism and protected areas using arid lands that cannot be reclaimed for agriculture, and renewable energy cultivation. In 2019, [14] developed an unsupervised decision tree classification method to classify satellite images by using Landsat 5 TM data with spectral indices NDVI and NDWI to classify saltmarsh land cover into saltmarsh vegetation, mudflat, and open water. The study found that classification performance for different periods of the Western Scheldt was almost perfect for this site, as well as other satellite data can be used as well, and the use of unsupervised decision tree classification procedures is a step towards automated land cover classification. On another side, integration of hydrodynamic and water quality simulation model with remote sensing and GIS-based geospatial analysis model was adopted by [15] to develop a novel deterministic methodology for estimating the optimal sampling frequency of water quality monitoring systems. This novel methodology was used to obtain the optimal sampling frequency of water quality monitoring systems within the Al-Hammar Marsh. Also, [16] used remote sensing with GIS techniques, and American Landsat satellites with a spatial resolution $(30 \mathrm{~m})$, the supervisory classification of these images were carried out by the Support Vector Machine (SVM) algorithm using ENVI 5.3v software, to monitor spatiotemporal changes in Al Razzazah Lake and its surrounding area for a period 1998- 2018, results showed that the lake area decreased by $86.21 \%$, and increasing the saline soil area by $64.97 \%$ in the study area in 2018 due to the continuous minimize in the lake water level. While, [17] applied three classification methods Maximum Likelihood Classification (MLC), 
Artificial Neural Networks (ANN), and Support Vector Machine (SVM), using multispectral satellite images Sentinel 2B images with a spatial resolution of $10 \mathrm{~m}$ on Al-Hawizeh marsh. The classification process carried out using ENVI 5.1 software to detect six land cover classes: deep-water marsh, shallow water marsh, marsh vegetation (aquatic vegetation), urban area (built-up area), agriculture area, and barren soil. The results showed that the MLC method applied provides higher overall accuracy and the kappa coefficient compared to the ANN and SVM methods. Overall accuracy values for MLC, ANN, and SVM methods were $85.32 \%, 70.64 \%$, and $77.01 \%$ respectively.

[18] combined remote sensing and GIS techniques, and developed a GIS model using the model-builder to prepare and analyze the data of imperviousness, land use land cover (LULC), and Hydraulic Soil group to estimate the runoff index in the urban watersheds of Baghdad city. Also [19]Implemented the Arc GIS model by using the model-builder to integrate the land degradation and produce the overall degradation map of the study area in Chamrajanagar district, Karnataka, India, based on the satellite imagery interpretation and soil map unit description. Remote sensing data was found to be useful tools to map land resources, especially in the areas where accessibility is limited like mountains.

Some researchers turned to evaluate the water quality of Al-Hammar Marsh after restoration by using the Canadian Council of Ministers of the Environment Water Quality Index (CCME WQI) for a different period [20] assessed water quality of the East Hammar for 2005- 2006. The results reflect that the marsh area is still far from the current guideline criteria and, too far from restoration, while [21] evaluated the water quality in Al-Hamedy Station, located in the middle of the marsh and related to the Al-Basra Governorate from 2011 to 2015, the Arithmetic Weighted Index was employed to determine the (WQI in the Al-Hammar Marsh, the results showed that the marsh water was brackish because of the high concentration of totally dissolved solids flowing in from the estuaries of the feeding channels coming from the river Euphrates, as well as from the tidal phenomenon via river Shatt Al-Arab.

Through the aforementioned review of previous studies, it can be noticed that there is no integrated and continuous evaluation of the effectiveness and efficiency of implementing the marsh restoration plan. Also, highlights the importance of applying effective evaluation methodologies using functional tools that ensure continuous spatiotemporal evaluation while reducing time, effort, and costs.

Accordingly, this paper aims to utilize remote sensing and GIS techniques to develop a satellite image-based indices model to monitor and evaluate the land cover of the wetlands. In this paper, the western part of the Al-Hammar Marsh was adopted as a case study to develop satellite images-based indices model to assess the land cover and the state of restoration of the western part of the Al-Hammar Marsh.

\section{Materials and Methods}

\subsection{Study area}

Al-Hammar Marsh is the largest water body in the southern part of Iraq. It is located to the right side of the Euphrates River between latitudes $\left(30^{\circ} 33^{\prime}-30^{\circ} 58^{\prime} \mathrm{N}\right)$ and longitudes $\left(46^{\circ} 24^{\prime}-47^{\circ} 39^{\prime} \mathrm{E}\right)$. It extends from near Al-Nasiriyah City in the west to the outskirts of Basra City on Shatt al-Arab River in the east, to the south it is bordered by saline lakes and the sand dune belt of the southern desert. Historically, this marsh area covers approximately $2800 \mathrm{~km} 2$ of permanent marsh and lake, expanding to over $4500 \mathrm{~km} 2$ during periods of seasonal and temporary inundation. The marsh was approximately $120 \mathrm{~km}$ long and $25 \mathrm{~km}$ wide with a maximum water depth ranging from 1.8 to $3 \mathrm{~m}$ [22].

Al-Hammar Marsh is separated by Al-Hammar dike into two parts. Western part of the Al-Hammar Marsh which is located in Thi-Qar province with area $1326 \mathrm{~km} 2$ shown in Figure 1, extending from near Al-Nasiriyah to the northwest of AlBasra Province in southern Iraq which feeds from many rivers, while the east part within Al-Basra City which is feeding by the tidal phenomenon through the Shatt Al-Arab River.

The Euphrates River and Main Outfall Drain (MOD) are the main water sources of western part of the Al-Hammar Marsh. The marsh is feeding by the AlKurmashia, UmNakhal and Al-Hamedy rivers. Also, the marshes are feeding by sub-rivers, which are the $\mathrm{BC} 3, \mathrm{BC} 3$ opining, $\mathrm{BC} 4, \mathrm{BC} 4$ opining, Central opening which sometimes work as feeders and other times as outlets, convey the water from Euphrates River to the marsh body and sometimes from the marsh to Euphrates River depending on the situation of water levels in the marsh and these rivers. Al-Khamissiya works as a feeder convey the water from the MOD to the marsh. However, the west part of the marsh is reconnected with the MOD at the southern-east by number of pipes to be the main outlet, Figure 1.

\subsection{Iraq's marsh restoration plans}

Based on many field surveys and implemented studies, IMoWR specified the restoration plans for the Iraq marshes to be $5.825 \mathrm{BCM}$ of fresh water allocated to the marshes in an average hydrological year, which will fill $50 \%$ of the CRIMWdelineated marshes, and help provide adequate flow to the Shatt al Arab. Additionally, proper land management and modernized agriculture will reduce soil degradation and prevent the loss of cultivated land to desertification. As a result, habitat and biodiversity can be protected in the marshes, in rivers, and in land that would have otherwise been degraded. The Iraq marshes restoration plans specified the total marshland freshwater surface consumption to be 5.388, 7.037, 6.554, 6.395 and $5.825 \mathrm{BCM} /$ year in 2015, 2020, 2025, 2030 and 2035 respectively. Also, it is recommended to provide an additional discharge of $2.611 \mathrm{BCM} / \mathrm{year}$ to the Al-Hammar Marsh. The Al-Hammar Marsh restoration plan included implementation of a diversion from the Euphrates into Al-Hammar Marsh downstream the Mother of Battle river and upstream the Al-Haffar regulator with a maximum capacity of $600 \mathrm{~m} 3 / \mathrm{s}$ to the wetland; implementation of a corresponding Al-Hammar outlet structure able to stand a maximum flow of $600 \mathrm{~m} 3 / \mathrm{s}$ [SWLR;2014]. 


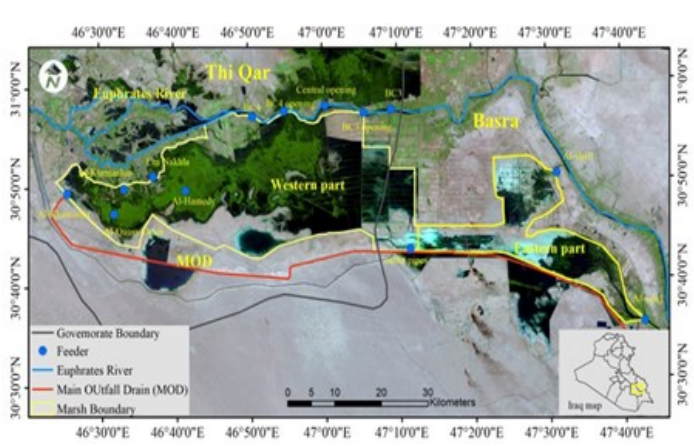

Figure 1: Location of the study area with Feeders and outlets

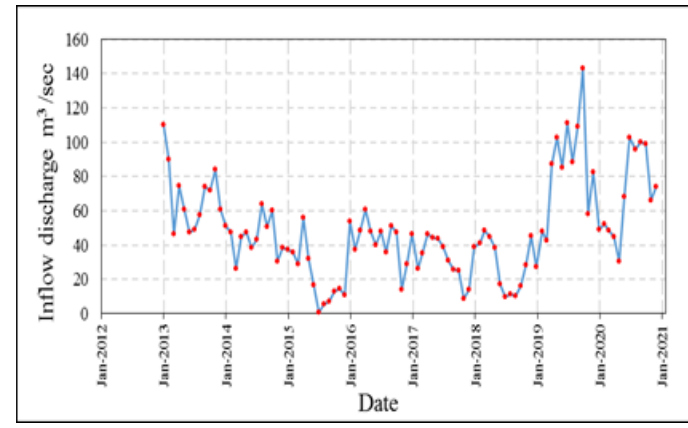

Figure 2: Monthly inflow discharge into western part of the Al-Hammar Marsh in $\mathrm{m} 3 / \mathrm{sec}$ recorded by (Based on CRIMW, 2020 unpublished data)

\subsection{Collected data}

\subsubsection{Western Part of Al-Hammar Marsh Inflow Discharge and Restored Areas}

The percentage rate of immersion area of the western part was calculated by the Center for the Restoration of Iraqi Marsh and Wetland (CRIMW, 2020 unpublished data) to the border between Thi-Qar and Basra shown in Table 1. While the inflow discharge covering the area to the dike between the two parts of the marsh, the average annual discharge inputting to Western part of the Al-Hammar Marsh from Euphrates river and Main Outfall Drain (MOD) is shown in Figure 2(CRIMW, 2020 unpublished data).

\subsubsection{Satellite Data Acquisition and Processing}

Landsat data are widely used for land cover classifications due to the reliability of their spatial resolution $(30 \mathrm{~m})$, revisit period (16 days), and spatial coverage $(185 \times 185 \mathrm{~km})$. The available Landsat data for the Al-Hammar Marsh are nonuniformly available for the analysis period from 2013 to 2020, and the spatial extent of the Al- Hammar Marsh is covered by two Landsat swaths, and as such the marsh can only be assessed when two temporally adjacent images are available. As a result, the images were available for the study area were listed in Table 2, and downloaded from the United States Geological Survey (USGS) with free cloud cover. The Landsat 8 images were successfully mosaicked after converting them to top-ofatmosphere spectral reflectance values to account for the radiometric contrast using ENVI 5.3 as shown in Table 3.

Table 1: Immersion rate of the Western part (to the border governorate) (CRIMW, 2020 unpublished data)

\begin{tabular}{lc}
\hline year & Immersion rate of Western part \% \\
\hline 2013 & 75.00 \\
2014 & 73.00 \\
2015 & 50.80 \\
2016 & 73.40 \\
2017 & 62.00 \\
2018 & 39.40 \\
2019 & 92.00 \\
2020 & 84.00 \\
\hline
\end{tabular}

Table 2: The available Landsat data for the Western Al Hammar Marsh

\begin{tabular}{ccccc}
\hline Satellite & Date of acquisition & Path/Row & Date of acquisition & Path/Row \\
\hline Land sat 8 & $12 / 07 / 2013$ & $166 / 39$ & $03 / 07 / 2013$ & $167 / 39$ \\
& $15 / 07 / 2014$ & $166 / 39$ & $06 / 07 / 2014$ & $167 / 39$ \\
$18 / 07 / 2015$ & $166 / 39$ & $09 / 07 / 2015$ & $167 / 39$ \\
& $05 / 08 / 2016$ & $166 / 39$ & $27 / 07 / 2016$ & $167 / 39$ \\
$23 / 07 / 2017$ & $166 / 39$ & $30 / 07 / 2017$ & $167 / 39$ \\
$27 / 08 / 2018$ & $166 / 39$ & $17 / 07 / 2018$ & $167 / 39$ \\
$27 / 06 / 2019$ & $166 / 39$ & $04 / 07 / 2019$ & $167 / 39$ \\
& $29 / 06 / 2020$ & $166 / 39$ & $06 / 07 / 2020$ & $167 / 39$ \\
\hline
\end{tabular}




\subsubsection{Spectral indices and evaluation model}

According to the nature of the Iraqi marshes area and previous studies related to the classification of the land cover there, the land cover classes can be divided into water, vegetation (dense vegetation, medium-density vegetation, low-density vegetation), wet soil, and dry barren land.

The Iraqi marshlands NDVI thresholds have been developed to describe the status of the marsh vegetation, a UNEP study showed that NDVI values greater than 0.125 represented vegetative cover [4]. Additionally, sparse vegetation was found to correspond to NDVI values between 0.125 and 0.25 , while medium-density vegetation was associated with NDVI values between 0.25 and 0.5 [4]. Dense vegetation was found to occur in areas with NDVI values over 0.5. In this paper, the same thresholds were adopted. On the other hand, NDMI reflects the levels of moisture in vegetation by contrasting the reflectance of the leaves' chlorophyll-a in the near-infra-red band to the leaf moisture absorbance in the shortwave infrared band. NDMI is also used to delineate wetted areas, given that NDMI values increases with water content. NDMI values greater than zero have been shown to correspond to wetted regions (water and wetland)[10]. Regions covered with (deep) water were identified based on their NDWI, with regions having NDWI greater than zero defined as regions with open water [23].

The spatial extent of the marshland overtime was classified based on a series of spectral-based indices included the Normalized Difference Vegetation Index (NDVI), the Normalized Difference Moisture Index (NDMI), and the Water Index (NDWI) as shown in table 4.

The methodology of spectral indices classification is shown in Figure 3 and summarized in the following points:

1) Identifying the wetted regions (NDMI $>0$ ) in the marsh by excluding all areas with an NDMI value less than zero. This region was defined as the spatial extent of the wet areas of the marsh. These areas were further divided into open water, vegetated areas, and wet non-vegetated areas according to the following criteria:

2) Open water regions were identified by (NDWI $>0$ ).

3) Vegetated areas were selected as those wet regions have NDMI $>0$ and that have an NDVI $>0.125$.

4) Non-vegetated marshland areas were the regions with NDMI $>0$, NDWI $<0$, and an NDVI $<0.125$.

5) Vegetated areas were further classified into low-density vegetated with $0.125<\mathrm{NDVI}<0.25$, mediumdensity vegetation with $0.25<\mathrm{NDVI}<0.5$, and dense vegetated NDVI $>0.5$, based on the UNEP-defined NDVI threshold [4].

A Geographic Information System (GIS) is a set of tools for analyzing, visualizing, and interpreting spatial and geographic data. Many studies in the engineering field now use GIS as a tool. Several menu/tools helped the user to analyze data. ArcGIS support user to make their model with a tool called the model builder. Model Builder is a visual programming language used to create geoprocessing workflows. It allows creating, editing, and managing workflows that link sequences of georeferenced processing tools and feed the output of one tool with other inputs, making it easier for the user to perform repetitive tasks in one step. Implementation of the model shown in Figure 3, was done by a GIS model builder.

Table 3: The available Landsat data for the Western Al Hammar Marsh

\begin{tabular}{|c|c|c|c|c|c|}
\hline Satellite & sensor & Path/Row & Year & Resolution (m) & Wavelength $(\mu \mathrm{m})$ \\
\hline Landsat 8 & OLI & $\begin{array}{l}166 / 39 \\
167 / 39\end{array}$ & $\begin{array}{l}2013 \\
2014 \\
2015 \\
2016 \\
2017 \\
2018 \\
2019\end{array}$ & 30 & $\begin{array}{l}\text { Band 3: } 0.533-0.590 \\
\text { Band 4: } 0.636-0.673 \\
\text { Band 5: } 0.851-0.879 \\
\text { Band 6: } 1.566-1.651\end{array}$ \\
\hline
\end{tabular}

Table 4: Spectral indices are used to classify the AL-Hammar Marsh

\begin{tabular}{ccc}
\hline Index & Equation & Reference \\
\hline Normalized Difference Vegetation Index & $N D V I=(N I R-R) /(N I R+R)$ & {$[24][25]$} \\
Normalized Difference Water Index & $N D W I=($ Green $-S W I R 1) /($ Green $+S W I R 1)$ & {$[26]$} \\
Normalized Difference Moisture Index & $N D M I=(N I R-S W I R 1) /(N I R+S W I R 1)$ & {$[27]$} \\
\hline
\end{tabular}




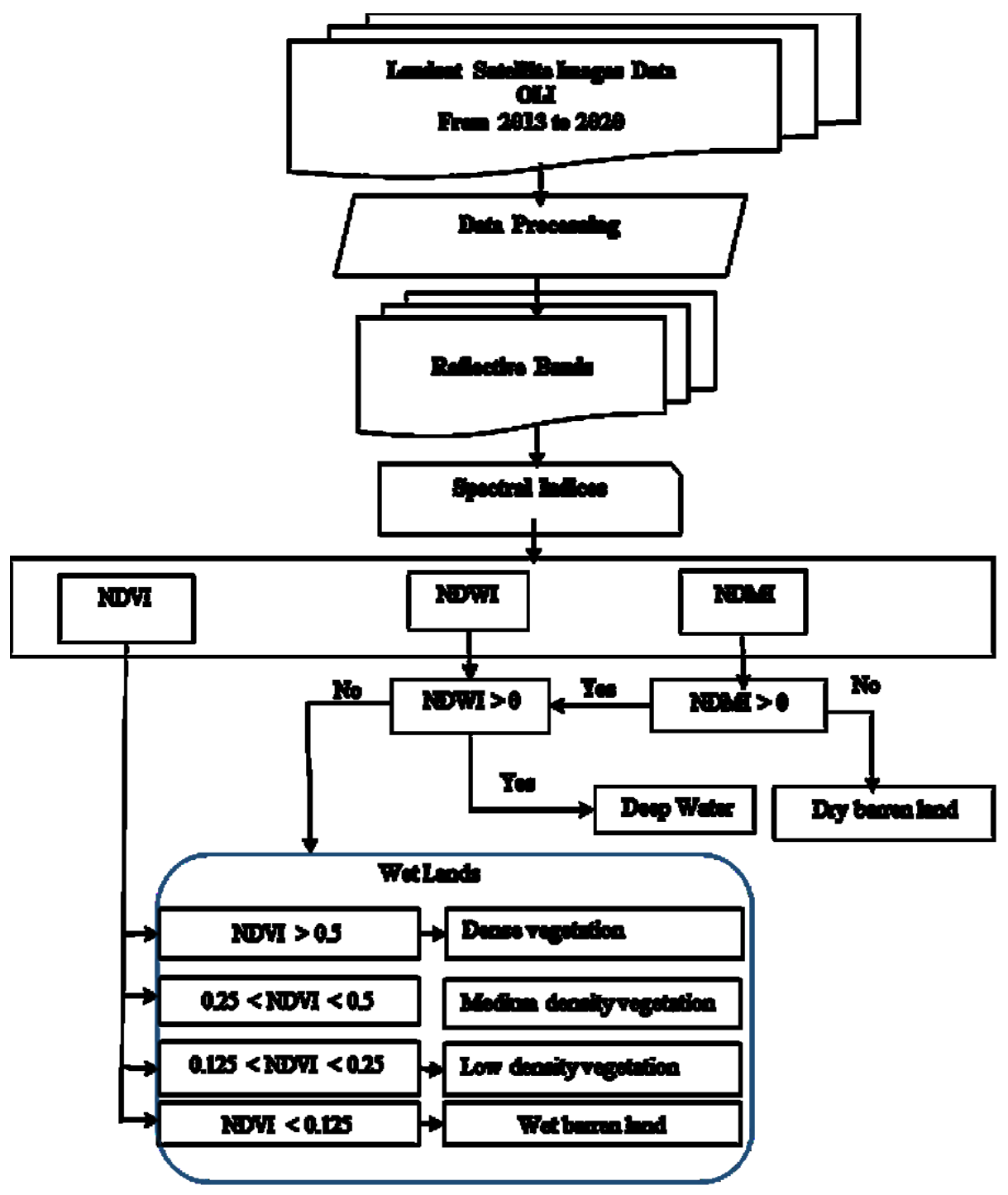

Figure 3: Schematic diagram of the marshland cover classification

\section{Result and Discussions}

\subsection{Satellite images-based indices model}

To extract the land cover of AL-Hammar Marsh, based on the methodology shown in Figure 3, the model builder of ArcGIS 10.4 was created as shown in Figure 4.

The Raster Calculator tool provides a selection of commonly used conditional and mathematical tools, allowing the user to easily add them to the expression. In model builder, the raster calculator was used in two stages, the first stage to calculating the spectral indices, while the second stage to implementing conditional equations mentioned in Figure 3. Finally, the model was saved as a toolbox and be ready for use as shown in Figure 5. Where deep-water represent the water category, dense represent dense vegetation cover, medium represents medium density vegetation, low represent low-density vegetation, shallow represent wet barren land and, dry represented dry barren land.

The obtained land cover maps via application of the implemented Satellite Images-Based Indices Model are shown in Figure 6. These maps show that most vegetation cover is distributed within the northern two-thirds of the western part of the Al-Hammar marsh. However, most of the southern third of the marsh is immersed with water for most of the studied period. Moreover, the barren lands are distributed along the boundaries of the marsh, while the distribution of the immersed areas and the vegetation cover is mainly concentrated in the central part of the marsh. The protection dikes of oil projects also appears clearly in the form of straight vertical lines, especially in the years 2018 and 2016 when decreasing water area. 


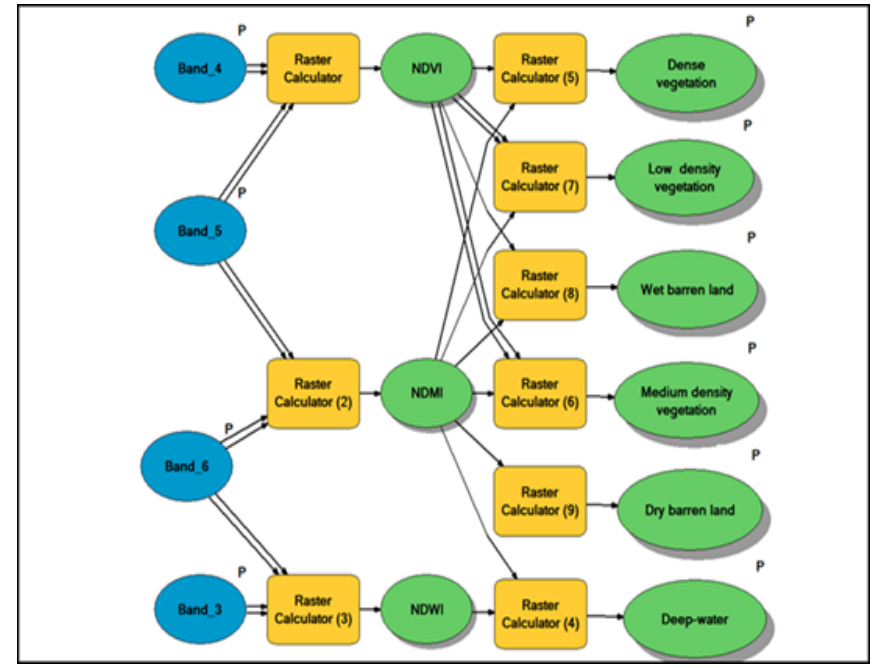

Figure 4: Model builder to classify the land cover of western part of the Al-Hammar Marsh

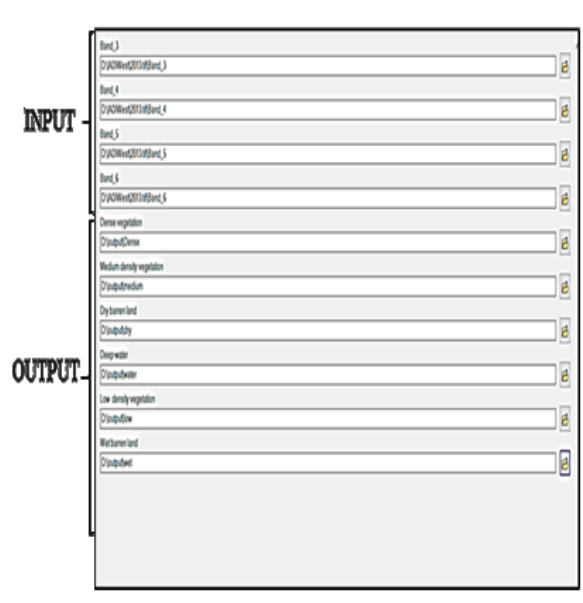

Figure 5: Input and output menu
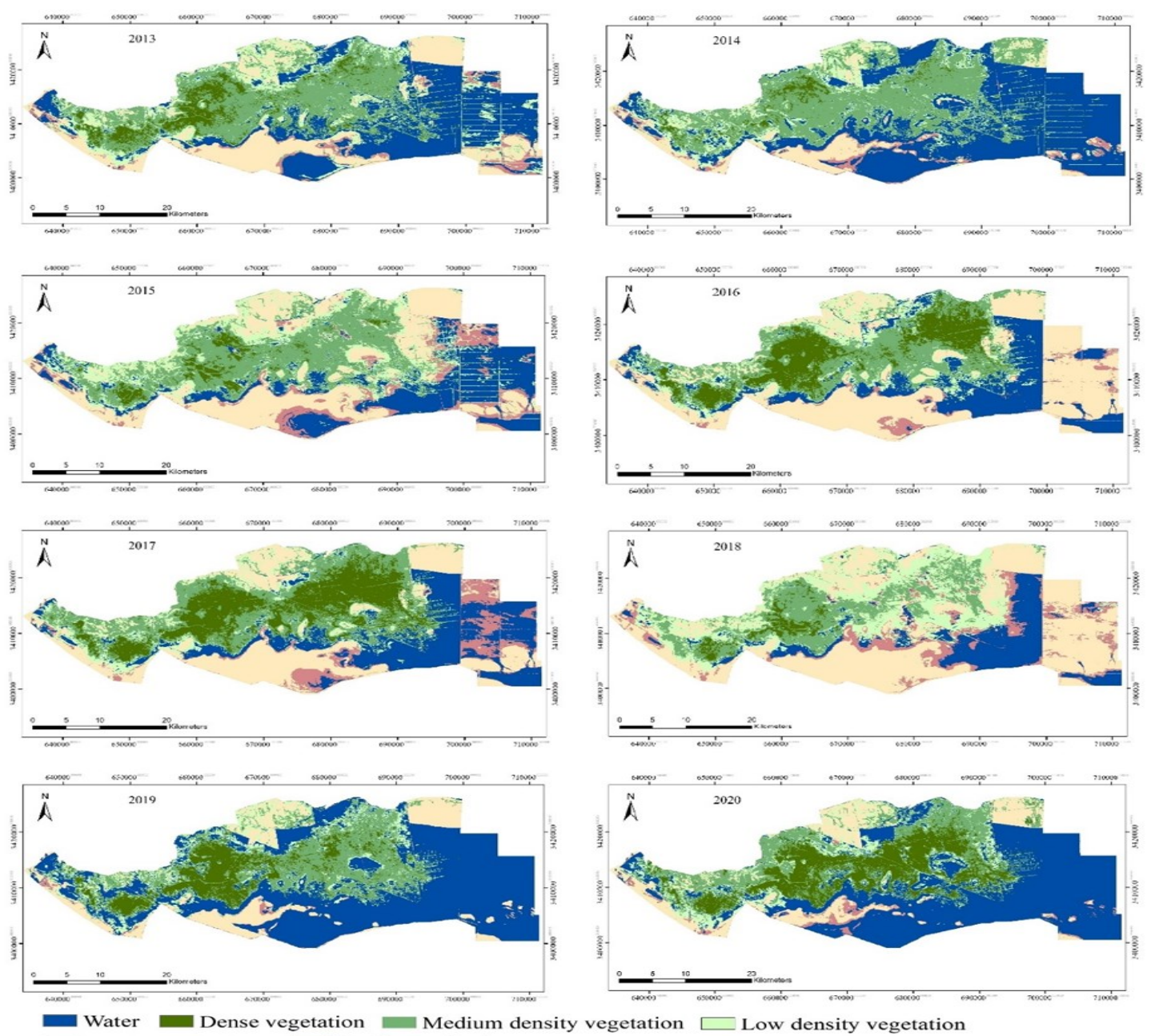

$\square$ Wet barren land $\square$ Dry barren land

Figure 6: Land cover Categories of Western part of the Al-Hammar Marsh obtained from satellite Images-Based Indices Model 
The categorization of the obtained maps shows the variability of the land cover classes, as shown in Figure 7, water areas increased for the years 2014,2019 , and 2020 , to be $42.65 \%, 47.33 \%$, and $42.85 \%$ from the total area of the marsh respectively,the highest percentage was in 2019 when the water class is $627.64 \mathrm{~km} 2$, While the percentage decreased in the remaining years to the lowest rate of $14.05 \%$ for the year 2018 .

While the barren areadecreased in 2014 and 2019 , to $11.11 \%$ and $12.81 \%$ and increased to its highest value $46.38 \%$ of the total area in 2018 respectively from the total area, The lowest barren land area during the study period was in 2014 , it was $147.33 \mathrm{~km} 2$. As for the vegetation cover, it increased in the years 2013,2017 , and 2020 to $49.38 \%, 48 \%$, and $44.14 \%$ from the total area, respectively, and decreased in 2018 and 2019 to $39.54 \%$ and $39.84 \%$ of the total area respectively. In general, variation in vegetation cover was slight, where the lowest percentage was $39.54 \%$ in 2018 and the highest was $49.38 \%$ in 2013 .

The variation of vegetation cover during the study period is computed form the obtained maps, as a result of applying the Satellite Images-Based Indices Model, The computed areas of the dense, medium and low density vegetation, as well as the total area of vegetation cover, are shown in Figure 8 . These areas show a slight decrease in vegetation cover from $49.38 \%$ of the total area in 2013 to $44.86 \%$ in 2016 as shown in Figure 8, then increased to 48\% in 2017. In 2018 and 2019 , the area of vegetation cover decreased to $39.54 \%$ and $39.84 \%$, respectively. However, it increased to $44.14 \%$ in 2020 .

The highest area of vegetation cover during the study period was $654.72 \mathrm{~km} 2$ in 2013 and the lowest area was $585.34 \mathrm{~km} 2$ in 2018.furthermore, deterioration of the dense vegetation cover was occurred in 2014when the percent of the vegetation reached to $2.23 \%$ of the total area, then gradually increasing to reach the highest value during the study period, as it was $17.94 \%$ in 2017 with an area of $237.86 \mathrm{~km} 2$. Then, the percentage decreased in 2018 to $2.44 \%$, while it increased in the years 2019 and 2020 to $9.78 \%$ and $15.81 \%$, respectively.

Medium-density vegetation significantly deteriorated from $30.60 \%$ in 2014 to $20.18 \%$ in 2016 , then increased slightly to $21 \%$ in 2017 and decreased in 2018 to $15.86 \%$ of the total area. Subsequently, it increased to $19.35 \%$ in 2019 and in 2020 its area decreased slightly to $18.04 \%$ of the total area.

Low-density vegetation areas fluctuated between increase and decrease, as they increased in 2015 and 2018 to $17.76 \%$ and $21.23 \%$ from the total area respectively, while it decreased in 2014,2017 , and 2019 to $13.53 \%, 9.06 \%$, and $10.72 \%$ respectively.

Barren land areas as shown in Figure 9 increased during the years 2015, 2016, and 2018 to 33.59\%, 36.52\%, and 46.38\% from the total area, respectively. The highest area was in 2018, as the area of barren land increased to $614.98 \mathrm{~km} 2$, while it decreased in 2014, 2019, and 2020 to $11.11 \%, 12.81 \%$, and $12.99 \%$, respectively.Most of the variation was in the dry barren class. There was a positive correlation between barren land and dry barren land classes. However, wet barren land areas fluctuated between increase and decrease. It increased for the years 2015 and 2018, and their percentage of the total area was $8.78 \%$ and $9.84 \%$. The highest percentage in 2018 was $130.44 \mathrm{~km} 2$ and then it decreased for the rest years to reach its lowest percentage in 2019 , which represents $1.25 \%$ of the total area.

From the above results, it can be seen that there is no improvement in the vegetation area, only a slight temporal improvement. Also, the use of spectral indices with processing operations in the GIS program by using the model builder was an effective way to monitor the trends of land cover change in the study area using the previous determinants without the need for training areas and can be used to evaluate the land cover of marshes in southern Iraq.

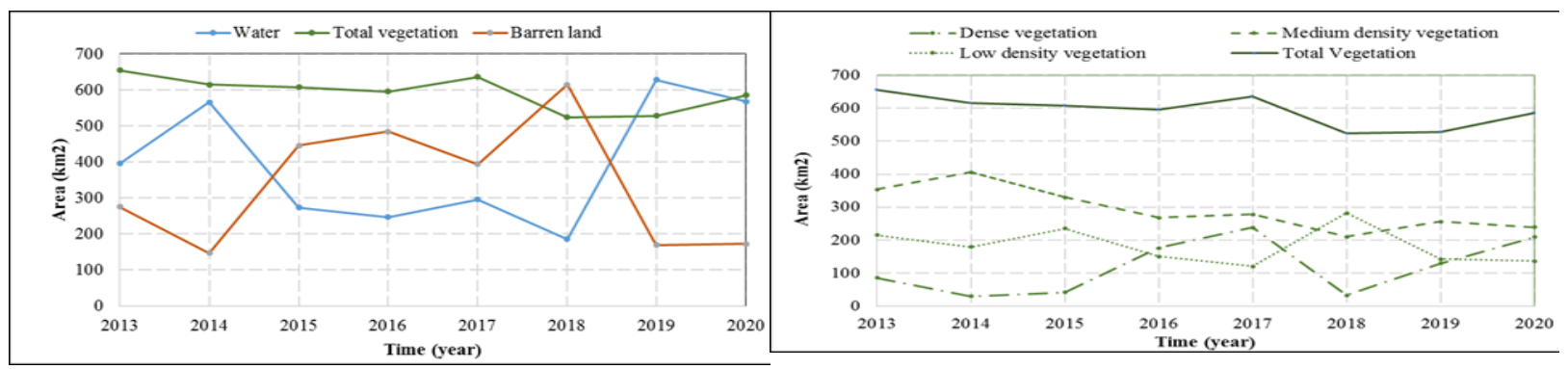

Figure 7: Variability of the land cover

Figure 8: Variability of vegetation cover classes

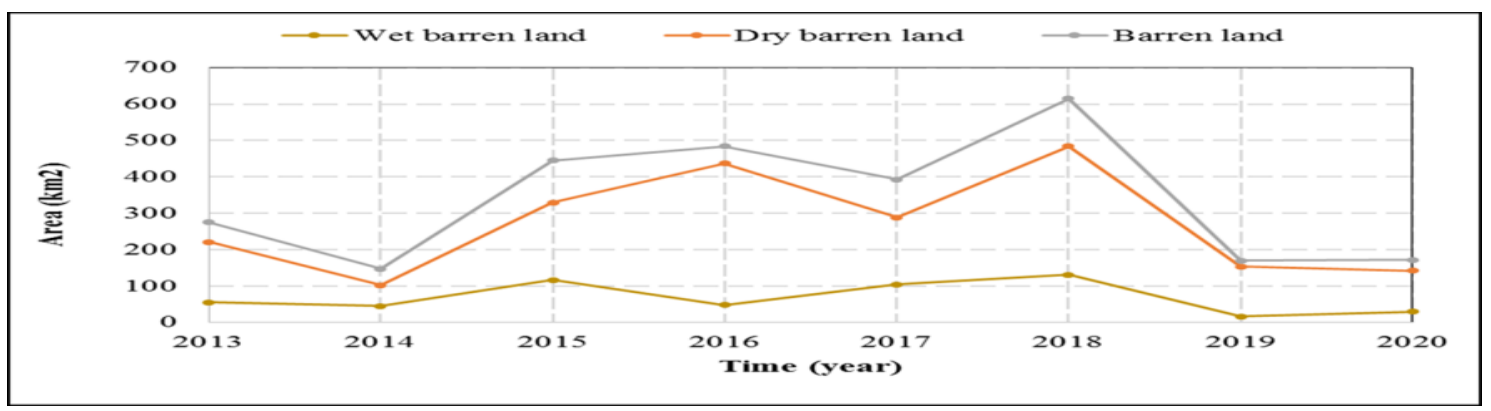

Figure 9: Variability of barren land class 


\subsection{Discussion}

This study presents a developed model by the model builder and three spectral indices NDVI, NDWI, and NDMI applied on Landsat satellite images to monitor western part of the Al-Hammar Marsh. Many research on engineering field were used the model builder, such as $[18,28,30]$.

Most of the researchers who monitored the land cover of marsh used supervised or unsupervised classification by using ERDAS, ENVI and, GIS programs. The obtained land cover classes were water, shallow water, marsh vegetation, urban area, an agricultural area, barren land. In 2021[17] applied three classification methods Maximum Likelihood Classification (MLC), Artificial Neural Networks (ANN), and Support Vector Machine (SVM), using multispectral satellite images Sentinel 2B images with a spatial resolution of $10 \mathrm{~m}$ on Al-Hawizeh marsh the result was six land cover classes: deep-water marsh, shallow water marsh, marsh vegetation (aquatic vegetation), urban area (built-up area), agriculture area, and barren soil. Also,[29] applied the supervised classification on Landsat satellite, MSS, TM, ETM, and OLI/TIRS to classify the Iraqi marshlands into the water, marsh vegetation cultivation, wetland, and barren land. On the other hand, some researchers found that the disadvantage of supervised classification that needed for training data sets for example [14] used two spectral indices NDVI and NDWI to classify saltmarsh land cover in Western Scheldt in Europe into three classes saltmarsh vegetation, mudflat, and open water using threshold limits commensurate with the study site. While, In this study three spectral indices NDVI, NDWI, and NDMI applied on Landsat satellite images with a spatial resolution of $30 \mathrm{~m}$ to extract the western Al-Hammar Marshland cover, the result was six classes: water, density vegetation, medium dense vegetation, low dense vegetation, wet barren land and, dry barren land. Although, the study area represented the areas eligible for floods after excluding agricultural areas and build-up areas.

From the monitoring of the changing trend, it is clear that there is no improvement in the vegetation area, only a slight temporal improvement in 2017, an increase in water area for the years 2019 and 2020, and decreasing in 2015 and 2018. These results agree with [29]where the area of the marshes started to increase from 2000 to 2020 overtime to approximately 4335 $\mathrm{km} 2$ towards the year 2020, except for a sudden decrease in 2015 and 2018.

\section{Conclusions}

The Iraqi marshlands NDVI thresholds for Landsat images that developed by UNEP Technical Report,2006[4] and used in this paper are suitable techniques for separating and monitoring the vegetation cover classes in the study area and southern Iraqi marsh.

According to the adopted physical principle, the mathematical representation and the applied algorithm of the developed model, it can be efficiently applied to other marshes areas.

By looking at the restoration plans for the AL-Hammar Marsh and the obtained land cover maps for the considered time period, it was found that the time series analysis is a beneficial method of describing and monitoring the changes in each land use category. Results obtained from the monitoring of the trend of the marsh land cover change, it is clear that there is no improvement in the vegetation area only a slight temporal improvement to be $48 \%$ in 2017 , an increase in water area for the years 2019 and 2020 to $47.33 \%$, and $42.85 \%$ from the total study area due to the flood in 2019 .

ArcGIS tools developed which allowed for model builder creation can be used effectively to allow redundancy and consistency in performing repetitive mathematical operations by eliminating human error factors and increase speed. Model builder is easy to save as a tool, sharing and rerunning from another user.

\section{References}

[1] N. Al-Ansari, "Can We Restore the Marches in Iraq (Garden of Eden)?," Engineering, Vol. 12, No. 07, pp. 466-486, 2020, doi: 10.4236/eng.2020.127033.

[2] [A. Allami, "UNEP-Iraq-marshlands-project-Final Complition Full Report-English,” 2009.

[3] C. R. Lane, H. Liu, B. C. Autrey, O. A. Anenkhonov, V. V. Chepinoga, and Q. Wu, "Improved wetland classification using eight-band high resolution satellite imagery and a hybrid approach," Remote Sens., Vol. 6, No. 12, pp. 12187-12216, 2014, doi: $10.3390 /$ rs61212187.

[4] UNEP, "Iraqi marshlands oservation system UNEP technical report," 2006, [Online]. Available: https://postconflict.unep.ch/publications/UNEP_IMOS.pdf.

[5] A. R. T. Ziboon, R. Z. Al Zubaidy, and M. S. Al Khafaji, "Remote sensing model for monitoring trophic state of Al Huweizah marsh,” Eng Tech. J., Vol. 28, No. 16, pp. 5213-5222, 2010, [Online]. Available: www.pdffactory.com.

[6] M. F. A. Abdul Jabbar, A. F. Al-ma, and A. T. Shehab, "Change detections in marsh areas, South Iraq, Using Remote Sensing and Gis Applications," Vol. 6, No. 2, pp. 17-39, 2010.

[7] I. J. Muhsin, F. K. Mashe, and Rafid J. Tawfeeq, "Monitoring the vegetation and water content of Al- Hammar marsh using remote sensing techniques abstract : introduction : materials and methods :," Baghdad Sci. J., Vol. 8, No. 2, pp. 646-651, 2011.

[8] Z. D. Hassan, "Using remote sensing techniques and geographic information systems ( GIS ) in sequences study to ALHammar marsh / south of Iraq for the period ( 1973-2010),’Vol. 3795, 2012. 
[9] M. J. Al Kazwini, M. S. Al Khafaji, and K. J. Hussain, "The hydraulic and environmental operation for the main outfall drain of Ad Dalmaj lake and Al Hammar marsh system the hydraulic and environmental operation for the main outfall Drain of Ad Dalmaj Lake and Al Hammar Marsh System.," Eng. \&Tech. J., Vol. 31, No. 15, 2013.

[10] K. Rokni, A. Ahmad, A. Selamat, and S. Hazini, "Water feature extraction and change detection using multitemporal landsat imagery," Remote Sens., vol. 6, no. 5, pp. 4173-4189, 2014, doi: 10.3390/rs6054173.

[11] A. G. Khalaf, G. H. Mohammed, and A. A. Jaseem, "Monitoring change of marshes In south of Iraq by using image processing techniques for landsatimages through period from 1990 to 2015," Eng. Technol. J., Vol. 34, No. 9, pp. 261274, 2016.

[12] H. S. Abdullah, M. S. Mahdi, and H. M. Ibrahim, "Water quality assessment models for Dokan Lake using Landsat 8 OLI satellite images," J. Zankoy Sulaimani, Pure Appl. Sci. 19-3, Vol. 4, pp. 25-44, 2017.

[13] M. M. Kadhim, "Monitoring land cover change using remote sensing and GIS techniques: a case study of Al-Dalmaj marsh, Iraq," Int. J. Heat Mass Transf., Vol. 24, no. 2, pp. 247-248, 2018, doi: 10.1016/0017-9310(69)90071-4.

[14] [M. L. Laengner, K. Siteur, and D. van der Wal, "Trends in the seaward extent of saltmarshes across Europe from longterm satellite data," Remote Sens., vol. 11, No. 14, pp. 1-25, 2019, doi: 10.3390/rs11141653.

[15] M. S. Al-Khafaji, "Deterministic methodology for determining the optimal sampling frequency of water quality monitoring systems," Hydrology, Vol. 6, No. 4, pp. 1-20, 2019, doi: 10.3390/HYDROLOGY6040094.

[16] A. H. Ali and H. S. Jaber, "Monitoring degradation of wetland areas using satellite imagery and geographic information system techniques," 2020.

[17] I. A. Alwan and N. A. Aziz, "An accuracy analysis comparison of supervised classification methods for mapping land cover using sentinel 2 images in the Al-Hawizeh marsh area, southern Iraq," Geomatics Environ. Eng., Vol. 15, No. 1, p. 5, 2021, doi: 10.7494/geom.2021.15.1.5.

[18] A. A. M. Ali, M. S. Mahdi, and N. J. Abdullah, "Gis model for producing hydraulic soil group classification digital map of Baghdad city," no. October, 2015.

[19] M. A. E. AbdelRahman, A. Natarajan, R. Hegde, and S. S. Prakash, "Assessment of land degradation using comprehensive geostatistical approach and remote sensing data in GIS-model builder," Egypt. J. Remote Sens. Sp. Sci., Vol. 22, No. 3, pp. 323-334, 2019, doi: 10.1016/j.ejrs.2018.03.002.

[20] A. Al-Saboonchi, A.-R. M. Mohamed, A. H. M. J. Alobaidy, H. S. Abid, and B. K. Maulood, "On the current and restoration conditions of thesouthern Iraqi marshes: application of the CCME WQI on east Hammar marsh," J. Environ. Prot. (Irvine,. Calif)., Vol. 02, No. 03, pp. 316-322, 2011, doi: 10.4236/jep.2011.23035.

[21] N. O. Al-Musawi, S. K. Al-Obaidi, and F. M. Al-Rubaie, "Evaluating water quality index of al Hammar Marsh, south of Iraq with the application of GIS technique,” J. Eng. Sci. Technol., Vol. 13, No. 12, pp. 4118-4130, 2018.

[22] Z. A. Abdulraheem, “Allocating the best representative water quality monitoring station dadity,” p. M.Sc. Thesis, 2015.

[23] A. Fisher, N. Flood, and T. Danaher, "Comparing Landsat water index methods for automated water classification in eastern Australia,” Remote Sens. Environ., Vol. 175, pp. 167-182, 2016, doi: 10.1016/j.rse.2015.12.055.

[24] T. N. Carlson and D. A. Ripley, "On the relation between NDVI, fractional vegetation cover, and leaf area index," Remote Sens. Environ.,Vol. 62, No. 3, pp. 241-252, Dec. 1997, doi: 10.1016/S0034-4257(97)00104-1.

[25] F. N. Kogan, "Droughts of the late 1980s in the United States as derived from NOAA polar-orbiting satellite data," Bull. Am. Meteorol. Soc., Vol. 76, No. 5, pp. 655-668, 1995.

[26] B.-C. Gao, "NDWI-A normalized difference water index for remote sensing of vegetation liquid water from space," Remote Sens. Environ., Vol. 58, No. 3, pp. 257-266, 1996.

[27] E. H. Wilson and S. A. Sader, "Detection of forest harvest type using multiple dates of Landsat TM imagery," Remote Sens. Environ.,Vol. 80, No. 3, pp. 385-396, 2002.

[28] Di. Pa Hidayat and S. Andajani, "Development land erosion model using model builder GIS (case study: citepus watershed)," MATEC Web Conf.,Vol. 147, pp. 1-6, 2018, doi: 10.1051/matecconf/201814703003.

[29] M. M. Hason, I. S. Abbood, and S. aldeen Odaa, "Land cover reflectance of Iraqi marshlands based on visible spectral multiband of satellite imagery," Results Eng., Vol. 8, No. July, p. 100167, 2020, doi: 10.1016/j.rineng.2020.100167. 